University of Nebraska - Lincoln

DigitalCommons@University of Nebraska - Lincoln

Faculty Publications: Department of Entomology

August 2005

\title{
Baseline Susceptibility of Western Corn Rootworm (Coleoptera: Crysomelidae) to Cry3Bb1 Bacillus thuringiensis Toxin
}

\author{
Blair D. Siegfried \\ University of Nebraska-Lincoln, bsiegfried1@ufl.edu \\ Ty T. Vaughn \\ University of Nebraska-Lincoln \\ Terrence A. Spencer \\ University of Nebraska-Lincoln, tspencer1@unl.edu
}

Follow this and additional works at: https://digitalcommons.unl.edu/entomologyfacpub

Part of the Entomology Commons

\footnotetext{
Siegfried, Blair D.; Vaughn, Ty T.; and Spencer, Terrence A., "Baseline Susceptibility of Western Corn Rootworm (Coleoptera: Crysomelidae) to Cry3Bb1 Bacillus thuringiensis Toxin" (2005). Faculty Publications: Department of Entomology. 46.

https://digitalcommons.unl.edu/entomologyfacpub/46
}

This Article is brought to you for free and open access by the Entomology, Department of at DigitalCommons@University of Nebraska - Lincoln. It has been accepted for inclusion in Faculty Publications: Department of Entomology by an authorized administrator of DigitalCommons@University of Nebraska - Lincoln. 


\section{Baseline Susceptibility of Western Corn Rootworm (Coleoptera: Crysomelidae) to Cry3Bb1 Bacillus thuringiensis Toxin}

Blair D. Siegfried, Ty T. Vaughn, and Terence Spencer

Journal of Economic Entomology

Volume 98, Issue 4 (August 2005) pp. 1320-1324

DOI: 10.1603/0022-0493(2005)098[1320:BSOWCR]2.0.CO;2

Authors may post electronic reprints of their own journal articles after an embargo period of two years has passed from the date of publication. Also, authors must include on the electronic reprint the following statement:

This article is the copyright property of the Entomological Society of America and may not be used for any commercial or other private purpose without specific written permission of the Entomological Society of America. 


\title{
Baseline Susceptibility of Western Corn Rootworm (Coleoptera: Crysomelidae) to Cry3Bb1 Bacillus thuringiensis Toxin
}

\author{
BLAIR D. SIEGFRIED, TY T. VAUGHN, ${ }^{1}$ AND TERENCE SPENCER \\ Department of Entomology, 202 Plant Industry Building, University of Nebraska, Lincoln, NE 68583-0816
}

\begin{abstract}
J. Econ. Entomol. 98(4): 1320-1324 (2005)
ABSTRACT Susceptibility to Cry3Bbl toxin from Bacillus thuringiensis (Bt) was determined for western corn rootworm, Diabrotica virgifera virgifera LeConte, neonates from both laboratory and field populations collected from across the Corn Belt. Rootworm larvae were exposed to artificial diet treated with increasing Cry3Bbl concentrations, and mortality and growth inhibition were evaluated after 4-7 d. The range of variation in Bt susceptibility indicated by growth inhibition was similar to that indicated by mortality. Although interpopulation variation in susceptibility was observed, the magnitude of the differences was comparable with the variability observed between generations of the same population. In general, the toxin was not highly toxic to larvae and estimated $\mathbf{L C}_{50}$ and $\mathrm{EC}_{50}$ values were several times higher than those reported for lepidopteran-specific Cry toxins by using similar bioassay techniques. These results suggest that the observed susceptibility differences reflect natural variation in Bt susceptibility among rootworm populations and provide a baseline for estimating potential shifts in susceptibility that might result from selection and exposure to Cry3Bb1expressing corn hybrids.
\end{abstract}

KEY WORDS Bt susceptibility, geographic variability, bioassay, Diabrotica virgifera virgifera

INCREASING PUBLIC CONCERN ABOUT environmental hazards and widespread resistance in pest populations is threatening the continued effectiveness of conventional insecticides. This threat is especially true for the western corn rootworm, Diabrotica virgifera virgifera LeConte, which is the most serious pest of field corn, Zea mays L., in North America. Crop rotation and chemical control have been the primary management strategies (Levine and Oloumi-Sadeghi 1991), although $D$. v. virgifera has become increasingly difficult to control due to its sequential ability to evolve resistance to different classes of small-molecule insecticides (Ball and Weekman 1962, Meinke et al. 1998, Zhou et al. 2002). In areas where crop rotation has been the primary management strategy, rootworms also have evolved a "behavioral" resistance involving oviposition in nonhost crops (O'Neal et al. 2001, Levine et al. 2002). Eggs deposited outside cornfields can cause significant damage to corn planted in these fields the following year. Soil insecticides such as organophosphates and pyrethroids are still effective, but they pose significant environmental and human health risks and are therefore unlikely to provide viable and longterm management options.

In 2003, the Monsanto Company announced it had received a registration from the U.S. Environmental Protection Agency for the sale of its YieldGard Root-

\footnotetext{
${ }^{1}$ Monsanto Co., 700 Chesterfield Parkway North, St. Louis, MO
} 63198 . worm-protected corn hybrids. This event (referred to as MON 863) constitutively expresses the Cry3Bb1 toxin derived from Bacillus thuringiensis $(\mathrm{Bt})$ in both root and above ground tissue, although only rootworm larvae are affected by the toxin (EPA 2003). This technology offers several important advantages over conventional rootworm management techniques, including reduced applicator exposure to insecticides and a narrower spectrum of activity, and it does not require special application equipment or calibration (Vaughn et al. 2005). However, as with other transgenic Bt crops, the risk of resistance development is perceived as being high, especially for MON 863, which does not express a high dose of toxin such that significant survival and adult emergence from expressing plants have been reported (Vaughn et al. 2005).

The development of $\mathrm{Bt}$ resistance in target pests threatens the continued effectiveness of Bt technology. The possibility of resistance development highlights the need to develop and implement resistance management strategies to prevent or delay the evolution of resistance to $\mathrm{Bt}$ (Hokkanen and Deacon 1994). These strategies are dependent on the development of effective resistance monitoring programs capable of early detection of resistance that allow implementation of appropriate management decisions in a timely manner (Dennehey 1987). The initial steps in implementing such programs include development of appropriate bioassay techniques and establishment of baseline susceptibility data among populations 
across the geographic range of the target species. With this information, potential population susceptibility changes in response to selection with Bt can be identified (Fischhoff 1996).

Documenting the variation in susceptibility to $\mathrm{Bt}$ toxins among geographically distinct populations has become a common theme in establishing sustainable resistance management programs. The objective of the current study was to establish a baseline of susceptibility to Cry3Bbl toxins from geographically distinct populations of western corn rootworms.

\section{Materials and Methods}

Insects. Western corn rootworm populations used for bioassays were either collected from the field or obtained from laboratory populations. Generally, laboratory populations were initiated from field-collected adults during 1995-1996 and reared for five to seven generations at the USDA-ARS Northern Grain Insects Research Laboratory in Brookings, SD, by using standard rearing techniques (Jackson 1986). Field populations were collected in 2002 as adults and were maintained on fresh corn silks, corn ears, and a water source according to Jackson (1986). Each collection consisted of at least 400 ovipositing females. The eggs from ovipositing females were collected in sifted soil by using standard techniques (Jackson 1986).

Eggs were shipped from the rearing facility and incubated at $25^{\circ} \mathrm{C}$ and $60 \% \mathrm{RH}$ for $12 \mathrm{~d}$. The eggs were then rinsed from the soil into a \#60 sieve, removing as much fine soil and debris as possible. Eggs were poured into a $50-\mathrm{ml}$ conical tube with excess water so that floating debris could be pored off. The remaining eggs were then suspended in $1.25 \mathrm{M} \mathrm{MgSO}_{4}$, which causes the eggs to float, whereas soil and other debris sink to the bottom so that they can be suctioned with a Pasteur pipette. $\mathrm{MgSO}_{4}$ flotation was repeated as necessary. The eggs were then disinfected to reduce microbial contamination by using techniques adapted from Pleau et al. (2002). Briefly, the eggs were cleaned first with Lysol brand disinfectant followed by $10 \%$ formalin for $2 \mathrm{~min}$ each and triple rinsed with sterile water. The eggs were pipetted onto Whatman no. 1 filter paper in petri dishes with vented lids and incubated at $28^{\circ} \mathrm{C}$ until hatching.

Bioassays. All bioassays were conducted by exposing neonates $(<24 \mathrm{~h}$ after hatching $)$ to treated artificial diet. Bioassays involved surface treatment of single wells of artificial diet dispensed into 96-well microtiter plates. The artificial diet used in all bioassays was prepared as described by Pleau et al. (2002). Bioassays were performed in 96-well microtiter plates (Falcon 353910, BD Biosciences, Franklin Lakes, NJ) . Approximately $200 \mu \mathrm{l}$ of diet was dispensed into each well by using an automated dispenser (Eppendorf 22-26400-1, Brinkman Laboratories, Westbury, NY) and allowed to solidify. Six concentrations of Cry3Bbl protein were used, and dilutions were made in $0.05 \%$ Triton X-100 nonionic detergent to obtain uniform spreading onto the diet surface. Each well was treated with $10 \mu \mathrm{l}$ of the appropriate solution.
Purified crystal Cry3Bbl protein was prepared from a B. thuringiensis strain (EG11231) containing the $\mathrm{Cry} 3 \mathrm{Bb} 1$ gene. This strain was grown in $\mathrm{C} 2$ medium for $3 \mathrm{~d}$ at $28^{\circ} \mathrm{C}$, at which time the cultures were fully sporulated and lysed. The spore and crystalline inclusions (i.e., crystals) were pelleted by centrifugation, and washed twice in $25 \mathrm{mM}$ Tris- $\mathrm{HCl}, 0.005 \%$ Triton $\mathrm{X}-100, \mathrm{pH} 7.5$. The washed pellet was resuspended in $25 \mathrm{mM}$ Tris- $\mathrm{HCl}, 2 \mathrm{mM} \mathrm{MgCl}{ }_{2}, 50 \mathrm{mM}$ phenylmethylsulfonyl fluoride, $\mathrm{pH} 7.5$, and treated with benzonase nuclease at $25 \mathrm{U} / \mathrm{ml}$ for $1.5 \mathrm{~h}$ at ambient temperature before centrifugation to the capture treated pellet. The resulting pellet was extracted in $4 \mathrm{M} \mathrm{NaBr}$ and incubated at ambient temperature for $2 \mathrm{~h}$ with stirring. The $4 \mathrm{M} \mathrm{NaBr}$ extract was then clarified by multiple centrifugations and subsequent filtration to $0.22 \mu \mathrm{m}$. The filtered extract was dialyzed against $10 \mathrm{mM}$ sodium acetate, $\mathrm{pH}$ 5.0, over 72-h period at which point a fine, white precipitate had fallen out of solution. This precipitated material was collected by centrifugation and washed once in $25 \mathrm{mM}$ Tris- $\mathrm{HCl}, 0.005 \%$ Triton $\mathrm{X}-100, \mathrm{pH} 7.5$, before final suspension in same buffer.

Cry3Bb1 protein quantification was determined by spot densitometry where multiple loadings of the Cry3Bbl protein were gel purified alongside bovine serum albumin (BSA) standards representing a fivepoint standard curve. The resulting Coomassiestained gel was scanned and analyzed, and the Cry3Bbl concentration was determined by direct comparison of band densities to the most linear portion of the BSA standard curve. Control treatments consisted of diet treated with $0.05 \%$ Triton X-100 only. Wells were allowed to air dry for $1 \mathrm{~h}$, and one neonate was transferred into each well by using a camel's-hair paintbrush. Wells then were covered with Mylar plate sealers (Dynex Technologies, Chantilly, VA), and plates were held at $27^{\circ} \mathrm{C}, 24$-h scotophase, and $80 \% \mathrm{RH}$. Mortality and individual larval weights were recorded 4-7 d later. All surviving larvae at each concentration were pooled, and the total weight was recorded.

Statistical Analysis. Only bioassays in which control mortality was $<20 \%$ and that had at least three concentrations that produced mortality $>0$ and $>100 \%$ were subjected to further statistical analysis. Bioassays were conducted in duplicate on three different dates, depending on availability of eggs, and they included at least five Bt concentrations that produced significant growth inhibition and mortality. Pooled weights of surviving larvae were recorded and transformed to percentage of growth inhibition relative to the controls, and these data were analyzed by nonlinear regression (SAS Institute 1988, Marçon et al. 1999). Mortality data were analyzed by probit analysis (Finney 1971) by using POLO-PC (LeOra Software 1987).

\section{Results and Discussion}

The susceptibility of neonate western corn rootworm larvae to the purified Cry3Bbl protein for laboratory and field populations is presented in Tables 1 and 2 , respectively. $\mathrm{LC}_{50}$ values ranged from $2.01 \mu \mathrm{g} /$ $\mathrm{cm}^{2}$ (Phelps Co., Nebraska) to $13.04 \mu \mathrm{g} / \mathrm{cm}^{2}$ (Potter 
Table 1. Susceptibility of western corn rootworm neonates exposed to the Cry3Bb1 toxin from B. thuringiensis as measured by growth inhibition and mortality from laboratory populations maintained for five or six generations

\begin{tabular}{|c|c|c|c|c|c|c|}
\hline Population & $n$ & $\mathrm{EC}_{50}(95 \% \mathrm{CI})^{a, b}$ & Slope $\pm \mathrm{SE}$ & $\mathrm{LC}_{50}(95 \% \mathrm{CL})^{b}$ & $x^{2}$ & $\overline{\mathrm{df}}$ \\
\hline Monsanto lab (2/2001) & 202 & $2.28(1.55-3.01)$ & $1.18 \pm 0.20$ & $5.57(1.02-14.70)$ & 3.45 & 3 \\
\hline Monsanto lab (3/2001) & 192 & $8.73(5.44-12.85)$ & $1.00 \pm 0.22$ & $13.04(5.01-27.77)$ & 0.22 & 2 \\
\hline Phelps Co., NE (Keene) & 275 & $1.85(1.32-2.54)$ & $1.32 \pm 0.17$ & $2.11(1.38-3.00)$ & 2.58 & 3 \\
\hline Phelps Co., NE (Nitchie) & 418 & $2.10(0.57-6.79)$ & $1.13 \pm 0.15$ & $2.01(0.75-3.75)$ & 13.13 & 8 \\
\hline Phelps Co., NE (Wenz) & 203 & $0.97(0.51-1.52)$ & $1.11 \pm 0.21$ & $2.18(0.90-3.93)$ & 0.99 & 3 \\
\hline Phelps Co., NE (Vandell) & 137 & $2.12(0.62-4.89)$ & $1.25 \pm 0.30$ & $4.62(1.90-8.23)$ & 0.74 & 2 \\
\hline Clay Co., NE & 198 & $2.71(1.86-3.96)$ & $1.17 \pm 0.20$ & $2.84(1.29-5.10)$ & 1.69 & 2 \\
\hline York Co., NE & 275 & $3.14(1.59-5.77)$ & $0.94 \pm 0.21$ & $7.92(3.62-14.75)$ & 1.79 & 2 \\
\hline Saunders Co., NE & 140 & $1.62(0.62-3.45)$ & $1.79 \pm 0.59$ & $2.38(0.23-4.81)$ & 0.77 & 3 \\
\hline Potter Co., SD & 115 & $4.14(2.77-5.19)$ & $1.41 \pm 0.39$ & $10.79(4.34-22.23)$ & 1.80 & 2 \\
\hline Tippecanoe Co., IN & 303 & $3.75(2.41-5.81)$ & $1.51 \pm 0.21$ & $4.14(2.59-5.98)$ & 2.86 & 3 \\
\hline Finney Co., KS & 244 & $1.67(1.41-1.98)$ & $1.70 \pm 0.21$ & $2.36(1.65-3.24)$ & 2.47 & 3 \\
\hline Champaign Co., IL & 292 & $1.95(1.55-2.43)$ & $1.08 \pm 0.17$ & $6.76(3.91-11.04)$ & 1.77 & 3 \\
\hline Center Co., PA & 164 & $2.49(2.12-2.93)$ & $3.07 \pm 0.84$ & $2.06(1.04-2.97)$ & 0.15 & 2 \\
\hline
\end{tabular}

${ }^{a}$ Concentration of Cry $3 \mathrm{Bbl}$ that produces $50 \%$ growth inhibition relative to untreated controls. Calculated by nonlinear regression fitted to a probit model. CI, confidence interval; CL, confidence limit.

${ }^{b}$ Micrograms of Cry3Bbl per square centimeter of treated artificial diet.

Co., South Dakota) in laboratory populations representing a six-fold difference in susceptibility (Table 1). Similar results were obtained with larval progeny derived from field-collected adults (Table 2), although variability was slightly greater with $\mathrm{LC}_{50}$ values ranging from $0.74 \mu \mathrm{g} / \mathrm{cm}^{2}$ (Winona Co, Minnesota) to $9.20 \mu \mathrm{g} / \mathrm{cm}^{2}$ (Weld Co., Iowa). Similar variation was observed in the calculated $\mathrm{EC}_{50}$ values for both laboratory (6.6-fold) and field (12-fold) populations. The generally higher variability observed in the field populations may reflect a more heterogeneous environmental and genetic background of the field populations.

Sigmoid curves were observed for both mortality and growth inhibition (Fig. 1), although there was not clear separation in the response curves. The relative absence of sublethal effects is reflected in the similarity of $\mathrm{LC}_{50}$ and $\mathrm{EC}_{50}$ values (Tables 1 and 2) among the populations tested. These results suggest that Cry3Bb1 does not cause significant sublethal effects as has been noted previously for lepidopteran-active Cry toxins that cause significant growth inhibition at concentrations that do not cause mortality (Marçon et al. 1999, Siegfried et al. 2000). Therefore, the toxin does not seem to be causing inhibition of growth at sublethal concentrations, and Cry3Bbl does not impact larval development at sublethal concentrations.

The results of these bioassays suggest that western corn rootworm larvae are in general not extremely sensitive to the Cry3Bb1 toxin because both $\mathrm{LC}_{50}$ and $\mathrm{EC}_{50}$ values are several orders of magnitude greater than values reported for lepidopteran-active Cry toxins by using similar bioassay methods. This lack of sensitivity is consistent with the designation of MON 863 as a low-to-medium dose product (EPA 2003). The designation of this technology as other than "high dose" is likely to be related to the inherent tolerance of D. v. virgifera to the Cry $3 \mathrm{Bbl}$ toxin. Although it is likely that there are multiple factors contributing to the survival of western corn rootworm larvae on MON 863 plants, it is also likely that the expression of toxin within these plants falls within the

Table 2. Susceptibility of western corn rootworm neonates derived from field populations exposed to the Cry3BbI toxin from B. thuringiensis as measured by growth inhibition and mortality

\begin{tabular}{|c|c|c|c|c|c|c|}
\hline Population & $n$ & $\mathrm{EC}_{50}(95 \% \mathrm{CI})^{a, b}$ & Slope $\pm \mathrm{SE}$ & $\mathrm{LC}_{50}(95 \% \mathrm{CL})^{b}$ & $\chi^{2}$ & $\mathrm{df}$ \\
\hline Yuma Co., CO & 397 & $1.46(0.60-3.39)$ & $1.51 \pm 0.20$ & $3.14(1.96-4.52)$ & 1.79 & 3 \\
\hline Scott Co., IA & 312 & $1.63(1.00-2.58)$ & $1.26 \pm 0.20$ & $1.49(0.73-2.45)$ & 1.14 & 3 \\
\hline Weld Co., IA & 321 & $1.97(0.92-3.88)$ & $1.42 \pm 0.18$ & $9.20(6.45-13.06)$ & 1.33 & 3 \\
\hline Iroquois Co., IL & 146 & $2.80(2.22-3.50)$ & $1.88 \pm 0.45$ & $4.22(1.99-6.75)$ & 1.96 & 2 \\
\hline Warren Co., IL & 155 & $0.98(0.76-1.24)$ & $2.05 \pm 0.48$ & $0.74(0.32-1.14)$ & 1.91 & 2 \\
\hline Gove Co., KS & 320 & $1.02(0.28-2.39)$ & $1.68 \pm 0.31$ & $4.90(2.51-7.40)$ & 0.99 & 3 \\
\hline Hamilton Co., NE & 459 & $1.06(0.91-1.21)$ & $1.44 \pm 0.15$ & $2.03(0.23-5.71)$ & $12.12^{c}$ & 3 \\
\hline Clay Co., NE & 293 & $1.47(0.48-4.12)$ & $1.49 \pm 0.21$ & $2.00(0.69-3.86)$ & 3.07 & 3 \\
\hline Seward Co., NE & 277 & $1.22(0.89-1.62)$ & $1.42 \pm 0.19$ & $2.69(0.82-5.79)$ & 4.67 & 3 \\
\hline Winona, MN & 494 & $0.52(0.35-0.64)$ & $1.91 \pm 0.23$ & $0.74(0.23-1.31)$ & 6.49 & 3 \\
\hline Ontario Co., NY & 408 & $1.12(0.88-1.39)$ & $1.94 \pm 0.19$ & $1.88(0.64-3.92)$ & $18.13^{c}$ & 3 \\
\hline Lancaster Co., PA & 289 & $2.26(0.92-5.60)$ & $1.16 \pm 0.15$ & $6.61(4.49-9.84)$ & 1.49 & 3 \\
\hline
\end{tabular}

${ }^{a}$ Concentration of Cry3Bbl that produces $50 \%$ growth inhibition relative to untreated controls. Calculated by nonlinear regression fitted to a probit model. CI, confidence interval; CL, confidence limit.

${ }^{b}$ Micrograms of Cry $3 \mathrm{Bbl}$ per square centimeter of treated artificial diet.

${ }^{c} \chi^{2}$ significant $(P<0.05)$. 


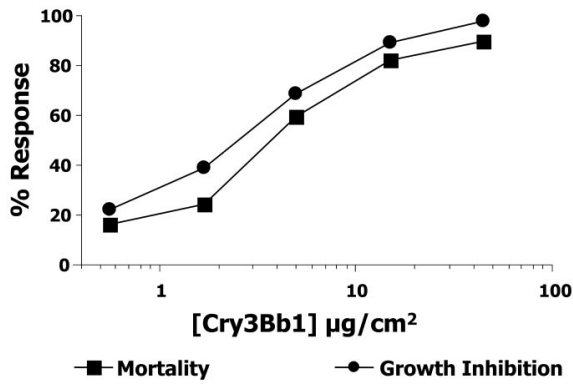

Fig. 1. Comparisons of response curves for mortality and growth inhibition of western corn rootworm neonate larvae exposed to increasing concentrations of the Cry3Bb1 $B$. thuringiesnis toxin.

normal distribution of tolerance among a susceptible homozygous population. Survival on MON 863 plants does not necessarily indicate a shift in the frequency of resistance alleles, and it is unlikely that initial frequency of major resistance-conferring alleles is any different than suggested for other species and other $\mathrm{Bt}$ endotoxins. Rather, it is more likely that expression of the toxin is comparable with a lethal dose that causes low-to-moderate mortality. As a consequence, a significant proportion of exposed populations may survive at the expressed levels and that MON 863 represents a truly low-to-moderate dose event.

Although variation in susceptibility to Cry $3 \mathrm{Bb} 1$ was observed, the magnitude of the difference was relatively small and similar to other estimates of baseline variability among geographically distinct populations of other insect species. Stone and Sims (1993) found considerable interpopulation variation in B. thuringiensis susceptibility to CrylAc and formulated Dipel among U.S. populations of both corn earworm, Helicoverpa zea (Boddie), and tobacco budworm Heliothis virescens (16- and 4-fold, respectively). These data were reexamined by Sims et al. (1996), who suggested that interpopulation variation in B. thuringiensis susceptibility may reflect nongenetic variation or sampling error, because the populations tested represented a small sample, taken at one point in time, of considerably larger multivoltine populations. Similar levels of variability in susceptibility to Cryl Ab and CrylAc were observed among European corn borer populations (Marçon et al. 1999) that included populations of different voltine ecotypes and pheromone strains and among geographically distinct populations of H. zea exposed to CrylAb (Siegfried et al. 2000).

The variation in baseline susceptibility to $B$. thuringiensis toxins may reflect differences in vigor among parental populations (Rossiter et al. 1990), attributes that are the product of both genotype and the maternally determined nutritional status of the egg. This variation may be especially evident of field populations where a higher degree of variation in maternal status is likely.

Development of baseline susceptibility data represents the first step toward the development of a monitoring program designed to detect changes in suscep- tibility that may result from repeated and prolonged exposure to B. thuringiensis toxins. These data also may provide information that will allow development of diagnostic bioassays that would be more efficient in detection of resistant populations. However, it should be noted that because of the relative insensitivity of rootworm to the Cry3Bb1 toxin, designation of diagnostic concentrations equivalent to an $\mathrm{LC}_{99}$ may be difficult to achieve because of the large amounts of purified crystal toxins that would be required for large scale testing of field populations.

\section{Acknowledgments}

We acknowledge the contributions of B. Koehler to data analysis. This research was supported through a grant to B.D.S. by Monsanto Co. This is journal series paper 14815, Nebraska Agricultural Research Division and contribution no. 1203 of the Department of Entomology, University of Nebraska.

\section{References Cited}

Ball, H. J., and G. T. Weekman. 1962. Insecticide resistance in the adult western corn rootworm in Nebraska. J. Econ. Entomol. 55: 439-441.

Dennehey, T. J. 1987. Decision-making for managing pest resistance to pesticides, pp. 118-126. In M. G. Ford, D. W. Holloman, B.P.S. Khanbay, and R. M. Sawicki [eds.], Combating resistance to xenobiotics: biological and chemical approaches. Ellis Horwood, Chichester, England.

[EPA] Environmental Protection Agency. 2003. Bacillus thuringiensis $\mathrm{Cry} 3 \mathrm{Bb} 1$ protein and the genetic material necessary for its production (vector zmirl3l) in event MON863 corn fact sheet. EPA Publ. No. 730-F-03-01.

Finney, D. J. 1971. Probit analysis. Cambridge University Press, Cambridge, England.

Fischhoff, D. A. 1996. Insect-resistant crop plants, pp. 214227. In G. J. Persley [ed.], Biotechnology and integrated pest management. CAB International, Wallingford, United Kingdom.

Hokkanen, H. M., and J. Deacon [eds]. 1994. OECD workshop on ecological implications of transgenic crop plants containing Bacillus thuringiensis toxin genes, pp. 395-609. In Biocontrol science \& technology vol. 4, no. 4. Carfax Publishing Company, Oxfordshire, United Kingdom.

Jackson, J. J. 1986. Rearing and handling of Diabrotica virgifera and Diabrotica undecipunctata howardi, pp. 25-47. In J. L. Krysan and T. A. Miller [eds.], Methods for the study of pest Diabrotica. Springer, New York.

LeOra Software. 1987. POLO-PC. A user's guide to probit and logist analysis. Berkeley, CA.

Levine, E., and H. Oloumi-Sadeghi. 1991. Management of diabroticite rootworms in corn. Annu. Rev. Entomol. 36: 229-255.

Levine, E., J. Spencer, S. A. Isard, D. W. Onstad, and M. E. Gray. 2002. Adaptation of the western corn rootworm, Diabrotica virgifera virgifera LeConte (Coleoptera: Chrysomelidae) to crop rotation: evolution of a new strain in response to a cultural management practice. Am. Entomol. 48: 94-107.

Marçon, P.C.R.G., L. J. Young, K. L. Steffey, and B. D. Siegfried. 1999. Baseline susceptibility of European corn borer (Lepidoptera: Crambidae) to Bacillus thuringiensis toxins. J. Econ. Entomol. 92: 279-285. 
Meinke, L. J., B. D. Siegfried, R. J. Wright, and L. D. Chandler. 1998. Adult susceptibility of Nebraska western corn rootworm (Coleoptera: Chrysomelidae) populations to selected insecticides. J. Econ. Entomol. 91: 594600 .

Pleau, M. J., J. E. Huesing, G. P. Head, and D. J. Feir. 2002. Development of an artificial diet for the western corn rootworm. Entomol. Exp. Appl. 105: 1-11.

O’Neal, M. E., M. E. Gray, S. Ratcliffe, and K. L. Steffey. 2001. Predicting western corn rootworm (Coleoptera: Chrysomelidae) larval injury to rotated corn with Pherocon AM traps I soybeans. J. Econ. Entomol. 94: 98-105.

Rossiter, M., W. G. Yendol, and N. R. Dubois. 1990. Resistance to Bacillus thuringiensis in gypsy moth (Lepidoptera: Lymantriidae): genetic and environmental causes. J. Econ. Entomol. 88: 1-10.

SAS Institute. 1988. SAS procedures guide, release 6.03 ed. SAS Institute, Cary, NC.

Siegfried, B. D., T. Spencer, and J. Nearman. 2000. Baseline susceptibility of the corn earworm (Lepidoptera: Noctuidae) to the CrylAb toxin from Bacillus thuringiensis. J. Econ. Entomol. 93: 1265-1268.
Sims, S. R., J. T. Greenplate, T. B. Stone, M. A. Caprio, and F. L. Gould. 1996. Monitoring strategies for early detection of Lepidoptera resistance to Bacillus thuringiensis insecticidal proteins, pp. 229-242. In T. M. Brown [ed.], Molecular genetics and evolution of pesticide resistance. American Chemical Society, Symposium Series, Washington, DC

Stone, T. B., and S. R. Sims. 1993. Geographic susceptibility of Heliothis virescens and Helicoverpa zea (Lepidoptera: Noctuidae) to Bacillus thuringiensis. J. Econ. Entomol. 86: 989-994.

Vaughn, T. T., T. Cavato, G., Brar, T. Coombe, T. DeGooyer, S. Ford, M. Groth, A. Howe, S. Johnson, K. Kolacz, et al. 2005. A method of controlling corn rootworm feeding using a Bacillus thuringiensis protein expressed in transgenic maize. Crop Sci. 45: 931-938.

Zhou, X., M. E. Scharf, S. Parimi, L. J. Meinke, R. J. Wright, L. D. Chandler, and B. D. Siegfried. 2002. Diagnostic assays based on esterase-mediated resistance mechanisms in western corn rootworms (Coleoptera: Chrysomelidae). J. Econ. Entomol. 95: 1261-1266.

Received 19 January 2005; accepted 25 April 2005. 